\title{
Intralobar Pulmonary Sequestration with Anomalous Artery Arising from the Celiac Trunk
}

\author{
Alexandr E. Mashkov ${ }^{1}$, Johannes M. Mayr ${ }^{2, *} \mathbb{D}$, Andrei V. Bobylev ${ }^{2}$ and Vyacheslav V. Slesarev ${ }^{1}$ \\ 1 Moscow Regional Research and Clinical Institute (MONIKI), 129110 Moscow, Russia; \\ malexe@yandex.ru (A.E.M.); vyach@inbox.ru (V.V.S.) \\ 2 Department of Pediatric Surgery, University Basel Children's Hospital, 4031 Basel, Switzerland; \\ andrei.bobylev@unibas.ch \\ * Correspondence: johannes.mayr@ukbb.ch; Tel.: +41-61-704-28-11
}

check for

updates

Citation: Mashkov, A.E.; Mayr, J.M.; Bobylev, A.V.; Slesarev, V.V. Intralobar Pulmonary Sequestration with Anomalous Artery Arising from the Celiac Trunk. Surgeries 2021, 2 , 105-112. https://doi.org/10.3390/ surgeries2010009

Received: 2 February 2021

Accepted: 15 February 2021

Published: 16 February 2021

Publisher's Note: MDPI stays neutral with regard to jurisdictional claims in published maps and institutional affiliations.

Copyright: (c) 2021 by the authors. Licensee MDPI, Basel, Switzerland. This article is an open access article distributed under the terms and conditions of the Creative Commons Attribution (CC BY) license (https:/ / creativecommons.org/licenses/by/ $4.0 /)$.

\begin{abstract}
Pulmonary saequestration is a rare congenital malformation characterized by a dysplastic portion of lung parenchyma supplied by an anomalous artery originating from the aorta or its branches. The worldwide incidence of pulmonary sequestration among all congenital lung malformations in children ranges from $1.5 \%$ to $6.4 \%$. There are two main types of pulmonary sequestration according to the localization of the malformation, i.e., intrapulmonary sequestration (dysplastic tissue located inside a lobe of the normal lung) and extrapulmonary sequestration. Our case presentation aims to make physicians aware of this rare anomaly which may be difficult to diagnose because of its oligosymptomatic course prior to first presentation. We present the case of a 10-year-old girl who suffered from a second episode of prolonged pneumonia of the left lower lobe. Contrastenhanced-computed-tomography (CT) scan of the thoraco-abdominal segment of the aorta and its branches revealed intrapulmonary sequestration localized at the left lower lobe of the lung. The intrapulmonary sequester was perfused by a large artery arising from the celiac trunk. The girl underwent open surgery with ligation of the anomalous feeding artery and atypical pulmonary resection of the affected area of the left lower lobe. Postoperatively, the child recovered without any complications.
\end{abstract}

Keywords: pulmonary sequestration; child; surgery; celiac trunk; contrast-enhanced computed tomography (CT)

\section{Introduction}

Pulmonary sequestration is a rare congenital abnormality where a dysplastic portion of the lung parenchyma is supplied by an anomalous systemic artery originating from the aorta or its branches [1-3]. In the early stages of embryogenesis, this pulmonary sequester is partially or completely separated from the normal lung parenchyma and develops independently. The majority of intrapulmonary sequestrations diagnosed prenatally tend to decrease in size after 28 weeks of gestation [4].

This congenital malformation is characterized by autonomic arterial blood supply (often by an anomalous artery of large diameter), abnormal bronchial development, and impaired development of lung parenchyma. There are two main types of pulmonary sequestration depending on the localization of the malformation, i.e., intrapulmonary sequestration (dysplastic tissue located inside a lobe of the normal lung) and extrapulmonary sequestration (pulmonary sequester located in an extra lobe of the lung) [5-8]. In most patients, the malformation is located in the left inferior lobe of the lung.

The ectopic variant of pulmonary sequestration with intra- or subdiaphragmatic localization is typically found in the area of the esophageal hiatus [9,10]. Bilateral pulmonary sequestration is exceptionally rare $[8,11]$. Abnormal feeding arteries can arise directly from the descending thoracic aorta or its branches (i.e., intercostal arteries, coronary vessels), but also from the pulmonary artery $[5,6,8,12,13]$. 
Surgical removal of the area of the lung affected by extrapulmonary or intrapulmonary sequestration or ectopic sequestration with ligation of the feeding artery is the method of choice for treating this congenital malformation [12,14]. Malignancies arising from the tissue of intralobar pulmonary sequesters have been reported rarely [15].

Our case description aims to alert physicians to this rare anomaly that may be difficult to diagnose because of its oligosymptomatic course prior to first presentation.

We obtained written informed consent from the patient's parents to publish this case report.

\section{Case Presentation}

Our 10-year-old female patient was referred to the Department of Pediatric Surgery at MONIKI Hospital, Moscow, Russian Federation, for treatment of recurrent pneumonia of the left lower lobe of the lung. Her body weight at admission was $29 \mathrm{~kg}$. During the past three years, the girl had undergone antibiotic treatment twice for left-sided pneumonia. Her medical history revealed that she had suffered from cough and fever ranging from $38.0^{\circ}$ to $39.4^{\circ}$ two weeks before being admitted to a regional pediatric hospital. She was diagnosed with severe acute respiratory syndrome (SARS) and tracheitis and received antibiotic treatment. Despite treatment for two weeks, her condition did not improve, and thus, she was referred to a regional hospital for intravenous antibiotic treatment of refractory pneumonia of the left lower lobe. CT scanning of the thorax revealed pneumonia of the inferior lobe of the left lung with localized destruction of lung parenchyma accompanied by pleural effusion. Subsequently, the girl was transferred to the Department of Pediatric Surgery at MONIKI Hospital for further treatment.

At admission to MONIKI Hospital, the girl was in poor general condition. Auscultation of the chest revealed weakened respiration sounds in the inferior area of the left side of the thorax. We administered intravenous antibiotics and physiotherapy. We suspected pulmonary sequestration as the cause of recurrent pulmonary infection and ruled out possible differential diagnoses.

\section{Differential Diagnoses}

Differential diagnoses of pulmonary sequestration comprise [16-19]:

- Recurrent pneumonia;

- Cystic adenomatous lung malformation;

- Communicating bronchopulmonary foregut malformation (CBPFM);

- Esophageal or gastric duplication cyst;

- Neuroblastoma;

- Tuberculosis of the lung.

\section{Investigations}

We performed multi-slice, contrast-enhanced CT scanning of the thorax and upper abdomen with subsequent multiplanar reconstruction. The lung tissue exhibited massive infiltration with cavities measuring $3 \mathrm{~mm}$ to $28 \mathrm{~mm}$ at the posterior-basal segment S10 of the left lower lobe (Figure 1).

There was no communication of the affected lung parenchyma with bronchi of the left inferior lobe. We noted no further infiltrative changes in the remainder of the left and right lungs. Contrast-enhanced CT scanning with 3D reconstruction showed normal configuration of the thoraco-abdominal aorta, celiac trunk, and renal arteries. The celiac trunk originated from the abdominal aorta at the level of the intervertebral space Th12-L1. The systemic feeding artery (proximal diameter of $5 \mathrm{~mm}$ ) originated from the celiac trunk. This artery supplied the pulmonary intralobar sequestration in the inferior lobe of the left lung (Figure 2a,b).

When comparing the chest CT images obtained by the regional hospital with our contrast-enhanced CT image, we noted a partial regression of dystelectatic areas within the left inferior lobe of the lung, reduced fluid within the cyst-like lesions, and reduced 
pleural effusion. Thus, we established the diagnosis of intrapulmonary sequestration of the inferior lobe of the left lung complicated by infection and pleural effusion.

The child's condition improved slowly. We decided to postpone surgical treatment for two months to allow pneumonia to resolve.

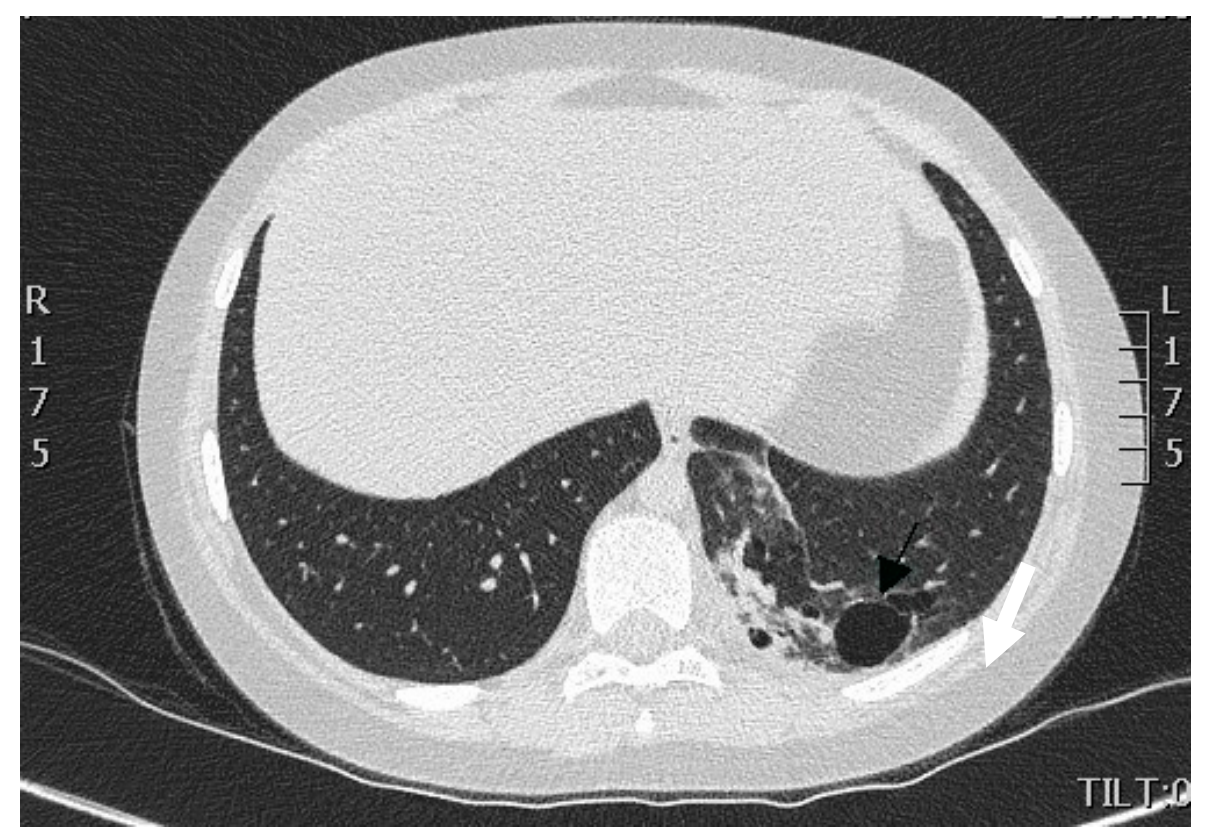

Figure 1. CT scan of the thorax. A portion of lung tissue contained cavities (indicated by arrow) and hyperdense scar formation located in the dorsomedial part of the lower lobe of the left lung.

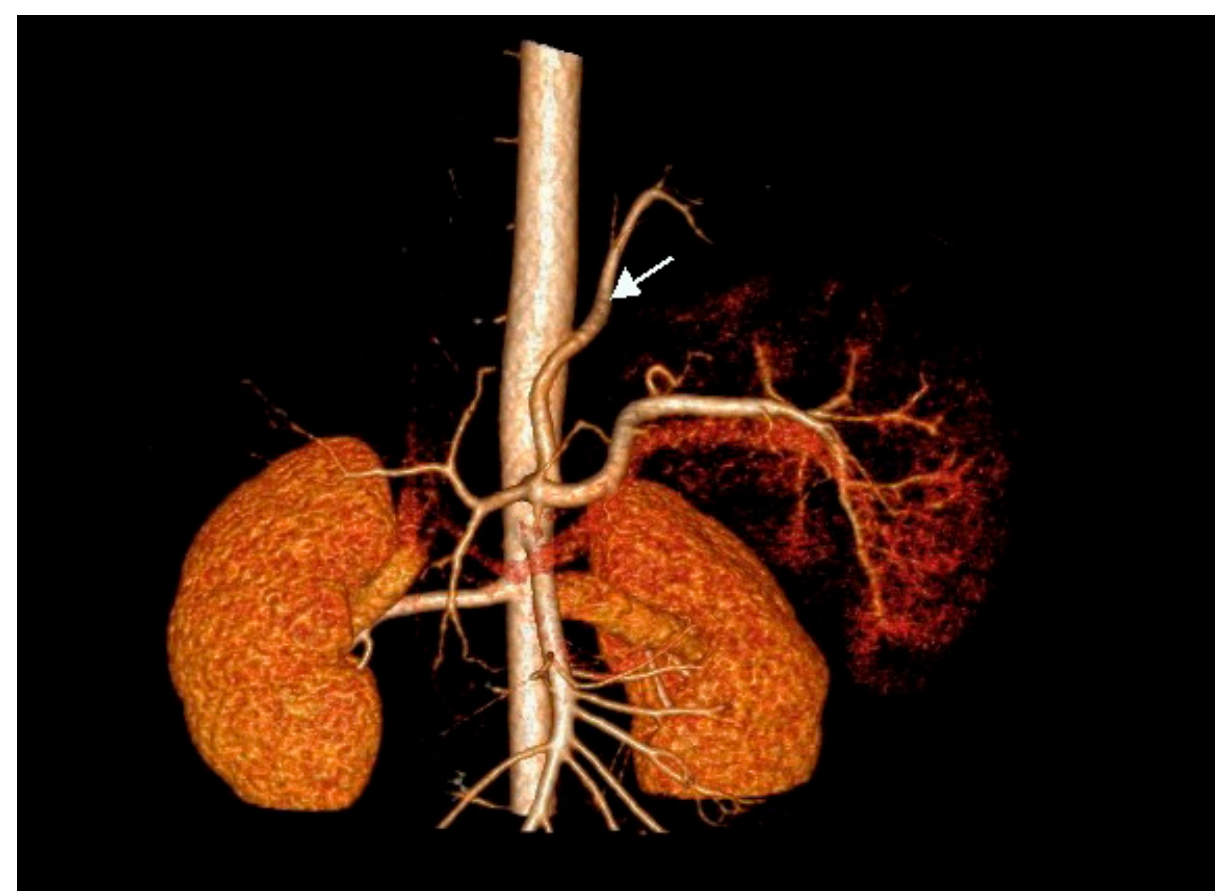

Figure 2. Cont. 


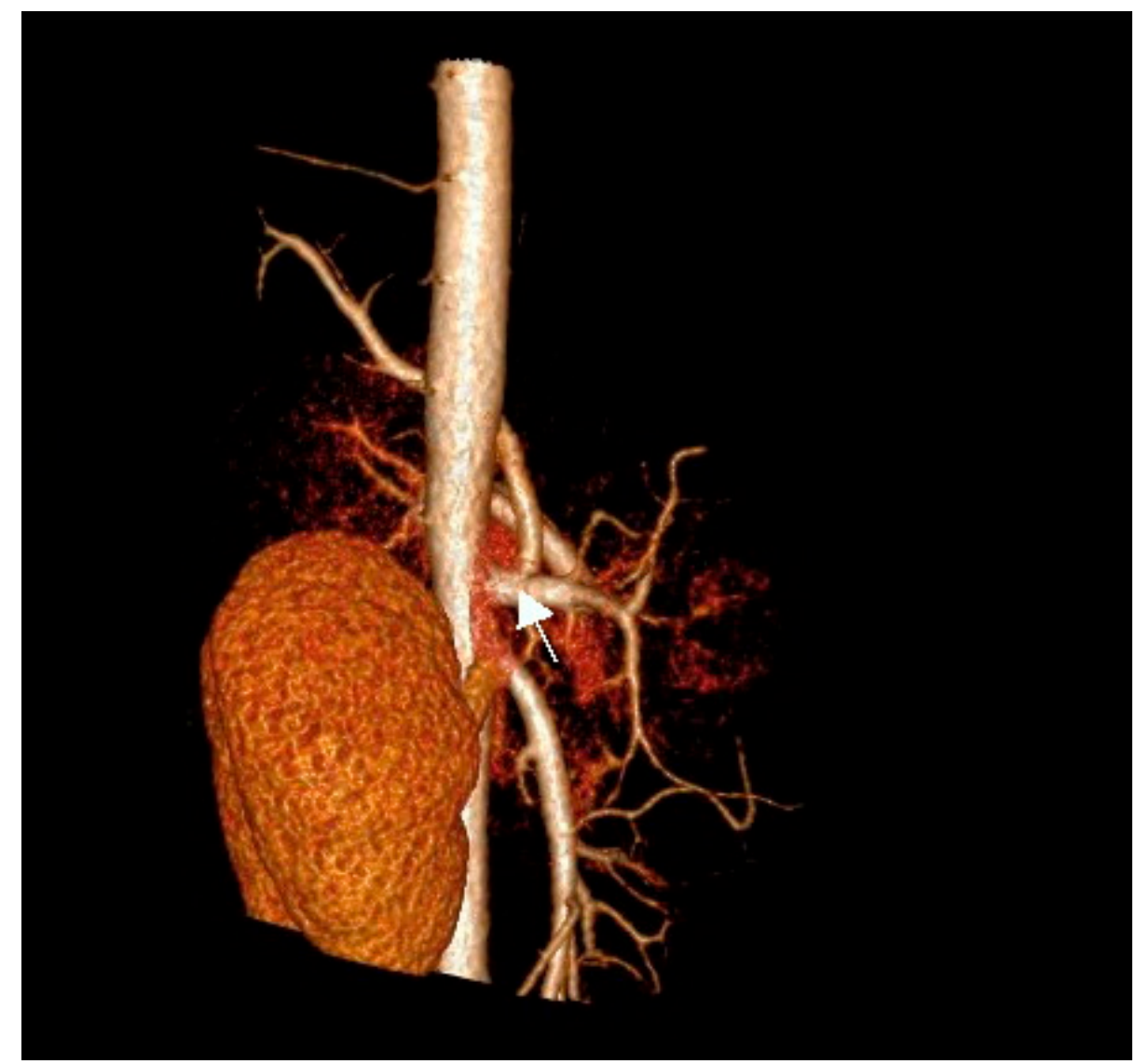

Figure 2. (a) Contrast-enhanced CT scan of the thoraco-abdominal aorta with 3D reconstruction of aorta, celiac trunk, and renal arteries. Note the feeding artery (indicated by arrow) with a diameter of $5 \mathrm{~mm}$ supplying the sequestration in the inferior lobe of the left lung (antero-posterior [AP] view). (b) Anomalous artery arising from the celiac trunk (artery indicated by arrow; lateral view).

\section{Treatment}

We performed left-sided posterolateral thoracotomy in the seventh intercostal space. The intrapulmonary sequester was characterized by an unventilated area of lung tissue at the posterior-basal segment (S10) of the inferior lobe. In accordance with CT findings, the pulmonary sequester was supplied by an arterial vessel with a diameter of $5 \mathrm{~mm}$. The artery traversed the diaphragm. We ligated the artery carefully before transection (Figure 3).

We carried out atypical resection of the sequester located in the inferior lobe of the left lung using a linear stapler. Histologic examination confirmed intralobar pulmonary sequestration with bronchiectases of different sizes, emphysema, and enlarged bronchi. Focal clusters of macrophages and lymphoid infiltrates were observed in the interalveolar septum and inside the lumen of alveoli.

\section{Outcome}

The postoperative course was without complications. Plain X-ray studies of the thorax obtained before the girl was discharged from the hospital confirmed the absence of infiltrates and pneumothorax (Figure 4). 


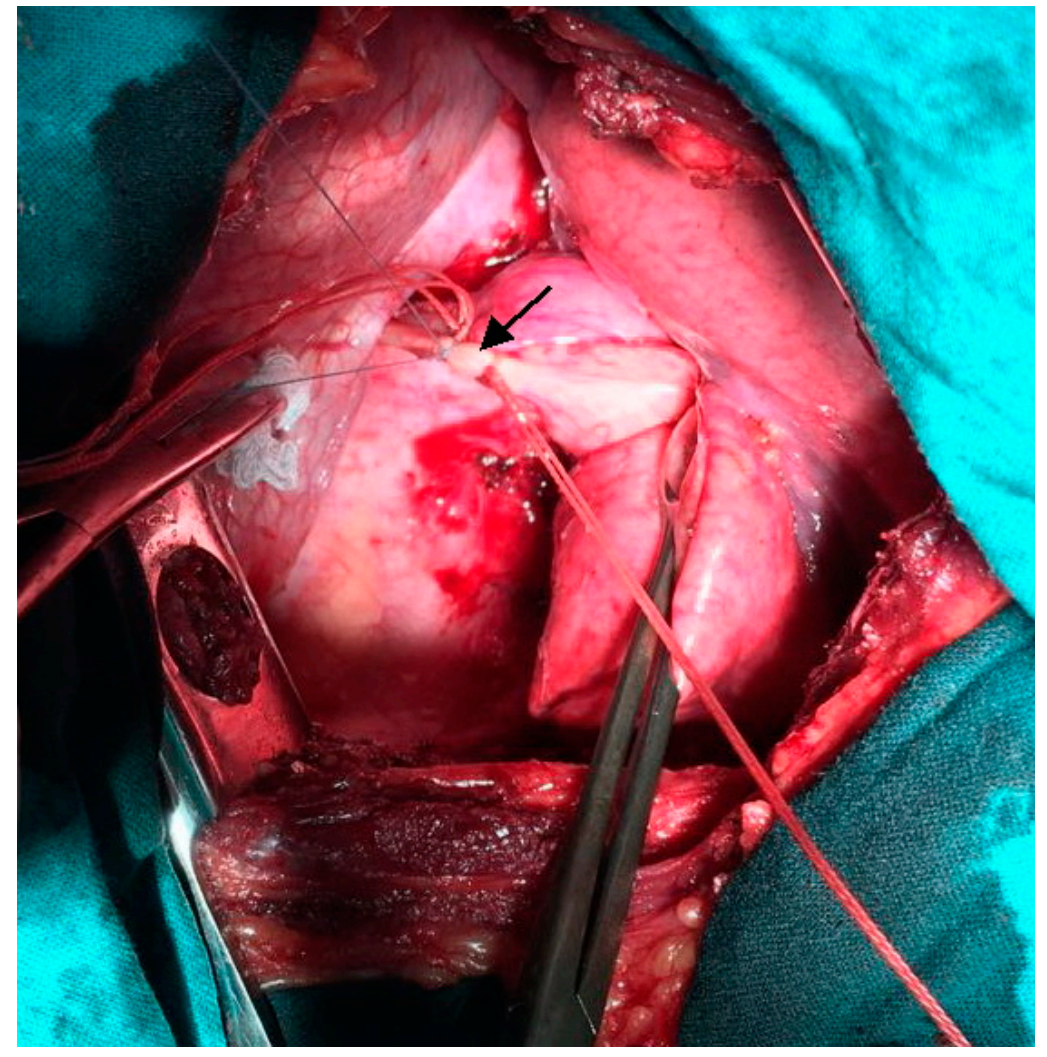

Figure 3. Intra-operative photograph: Ligation of the anomalous feeding artery (indicated by arrow) supplying the pulmonary sequester.

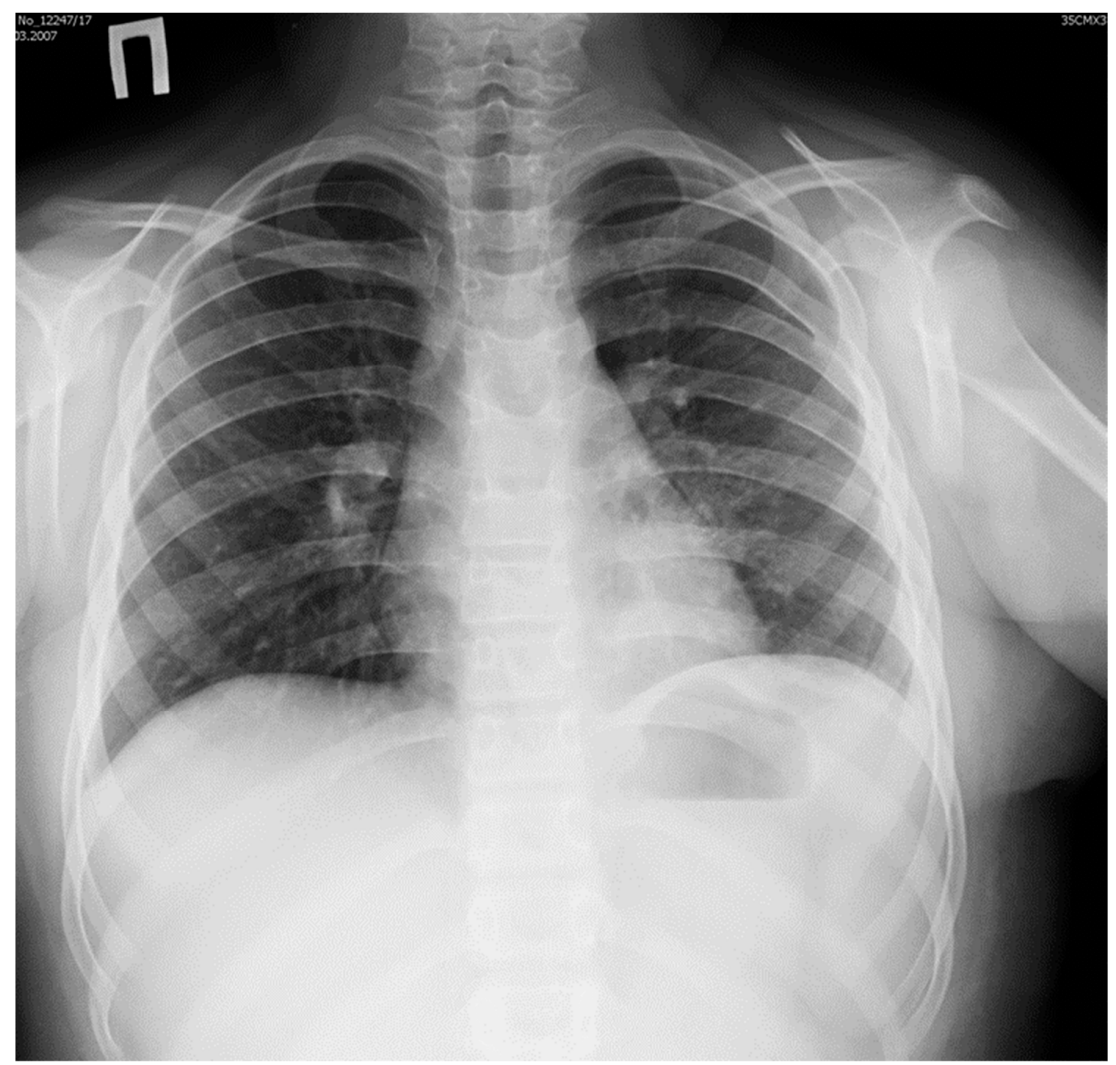

Figure 4. Plain X-ray image of the thorax obtained before discharge from hospital: normal appearance of left lung after resection of the pulmonary sequester. 
The diaphragm was in normal position, and sinuses were free of fluid. Blood tests did not show any signs of inflammation.

\section{Discussion}

Pulmonary sequestration is very rarely observed in children. However, pulmonary sequestrations represent the second most common lung malformation. Based on their location and histopathologic characteristics, three types are distinguished, i.e., intralobar sequestration, extralobar sequestration, and communicating bronchopulmonary foregut malformation (CBPFM) [17].

There are three main types of clinical presentation of pulmonary sequestration as described below [5].

\subsection{Cystic Type with Formation of Abscess}

The clinical picture of this type is characterized by chronic infection of lung lobes in the vicinity of the pulmonary sequester. Affected patients usually suffer from dry or productive cough for prolonged periods of time. Upon aggravation of infection, patients expectorate purulent sputum, suffer from chest pain at the affected site, and experience shortness of breath on exertion.

\subsection{Pseudotumor Type}

This type is characterized by minimal or absent clinical symptoms. Pulmonary sequestration is usually diagnosed incidentally when obtaining plain X-ray images of the thorax for other reasons. X-Ray images demonstrate a homogeneous, intense infiltrate with clearly defined margins.

\subsection{Bronchiectatic Type}

This type typically occurs because of a secondary communication between the sequester and bronchial tree after recurrent bacterial infections and suppurative destruction of lung parenchyma. The clinical picture corresponds to a chronic, recurrent inflammatory process of the lung complicated by pleural infection and effusion.

Pulmonary sequestration can be located in several regions of the thoracic and abdominal cavity [3].

To confirm the diagnosis of pulmonary sequestration and to follow up patients with congenital thoracic malformation (CTM) detected prenatally, it is necessary to carry out angiography or contrast-enhanced CT scanning of the thorax with subsequent reconstruction of the thoraco-abdominal aorta and its branches. These imaging studies demonstrate the anomalous feeding artery $[6-9,20]$.

The complications of pulmonary sequestration comprise infection, hemoptysis, pneumothorax, sudden respiratory compromise, and malignancies arising from the altered lung tissue [20]. The most frequently observed manifestation of intrapulmonary sequestration in children is recurrent infection, whereas in young adults, hemoptysis prevails [1].

Open thoracotomy or video-assisted thoracic surgery (VATS) with atypical resection of the pulmonary sequestration area or lobectomy is the treatment of choice [21]. Many authors still prefer open surgical access over thoracoscopic resection in children suffering from pulmonary sequestration. Open surgery permits easier control of hilar structures and ligation of the feeding artery even in the presence of dense postpneumonic adhesions and infiltrations. Correct identification and ligation of the aberrant artery is of crucial importance to avoid intra-operative bleeding complications [21]. Therefore, VATS is considered a valid surgical option in children suffering from pulmonary sequestration without dense adhesions of the hilar and diaphragmatic regions [21]. In our patient, we opted for thoracotomy because the child had suffered several pulmonary infections in the left lung segment 10 .

In recent years, thoracoscopy and VATS have gained increasing acceptance [7,22-25]. Laparoscopy is used for resection of ectopic forms of pulmonary sequestration $[9,10]$. 
Laparoscopy allows for improved visualization of ectopic extralobar pulmonary sequester located in the hiatal region of the diaphragm $[9,10]$. In a series of ectopic extralobar pulmonary sequestrations described by Joyeux et al., three lesions were located at the hiatal region, and three were located intra-abdominally [10]. The authors excised one lesion thoracoscopically and five lesions laparoscopically, but in two of these patients, the laparoscopic approach had to be converted to open abdominal surgery [10].

Some authors recommend endovascular embolization of pulmonary sequesters as a minimally invasive treatment option $[11,26]$. However, long-term outcome of pulmonary sequesters treated by embolization has not been studied in larger series of young patients [27]. Zhang et al. reported good outcomes after endovascular treatment of pulmonary sequesters in six adult patients and one child [28]. In contrast, Chakraborty et al. reported recurrence rates between $25 \%$ and $47 \%$ after endovascular intervention [29].

\section{Learning Points/Take-Home Messages}

Pulmonary sequestration may mimic recurrent pneumonia in children and may cause massive hemoptysis in young adults. All patients with suspected or prenatally confirmed CTM should undergo contrast-enhanced chest CT in early childhood. When performing resections or operating on lung malformations in children, it is of utmost importance to consider a possible pulmonary sequester supplied by a large, aberrant systemic artery. Inadvertent injury to the feeding artery of a pulmonary sequester can result in life-threatening intra-operative hemorrhage. Therefore, pre-operative embolization of the feeding artery is recommended by some authors. Other authors suggest cleaning and draping the skin of the upper abdominal and thoracic wall before operating pulmonary sequesters. This allows for emergency laparotomy if a bleeding arterial stump retracts into the retroperitoneum.

Author Contributions: A.E.M. conceptualization and review of the manuscript; J.M.M. revision of the manuscript and editing; A.V.B. data collection and formal analysis; V.V.S. writing of the manuscript and literature search. All authors have read and agreed to the published version of the manuscript.

Funding: We obtained no funding for this study.

Institutional Review Board Statement: Ethical review and approval were waived for this case report, due to the nature of this article (case report).

Informed Consent Statement: Informed consent was obtained from the parents of the patient involved in the study.

Data Availability Statement: Data is contained within the article.

Conflicts of Interest: The authors declare no conflict of interest.

\section{Abbreviations}

$\begin{array}{ll}\text { AP } & \text { Antero-posterior } \\ \text { CBPFM } & \text { Communicating bronchopulmonary foregut malformation } \\ \text { CT } & \text { Computed tomography } \\ \text { CTM } & \text { Congenital thoracic malformation } \\ \text { SARS } & \text { Severe acute respiratory syndrome } \\ \text { VATS } & \text { Video-assisted thoracic surgery }\end{array}$

\section{References}

1. Janah, H.; Belabbes, S.; Belasri, S.; Zidane, A.; Arsalane, A.; Fatihi, J. Une séquestration pulmonaire particulière A case of bronchopulmonary sequestration. Rev. Mal. Respir. 2019, 36, 543-546. [CrossRef]

2. Rubin, E.M.; Garcia, H.; Horowitz, M.D.; Guerra, J.J. Jr. Fatal massive hemoptysis secondary to intralobar sequestration. Chest 1994, 106, 954-955. [CrossRef]

3. Zhang, N.; Zeng, Q.; Chen, C.; Yu, J.; Zhang, X. Distribution, diagnosis, and treatment of pulmonary sequestration: Report of 208 cases. J. Pediatr. Surg. 2019, 54, 1286-1292. [CrossRef] [PubMed] 
4. $\quad$ Riley, J.S.; Urwin, J.W.; Oliver, E.R.; Coleman, B.G.; Khalek, N.; Moldenhauer, J.S.; Spinner, S.S.; Hedrick, H.L.; Adzick, N.S.; Peranteau, W.H. Prenatal growth characteristics and pre/postnatal management of bronchopulmonary sequestrations. J. Pediatr. Surg. 2018, 53, 265-269. [CrossRef]

5. Grebnev, P.N.; Osipov, A.Y. Diagnosis and surgical treatment of lung sequestration in children. Pract. Med. 2010, 6, 141-143.

6. Estes, M.E.Z. Bronchopulmonary sequestration: Improving practice by evaluating for a missed diagnosis. Nurse Pract. 2017, 42 , 51-55. [CrossRef]

7. Jesch, N.K.; Leonhardt, J.; Sümpelmann, R.; Gluer, S.; Nustede, R.; Ure, B.M. Thoracoscopic resection of intra- and extralobar pulmonary sequestration in the first 3 months of life. J. Pediatr. Surg. 2005, 40, 1404-1406. [CrossRef]

8. Wei, Y.; Li, F. Pulmonary sequestration: A retrospective analysis of 2625 cases in China. Eur. J. Cardiothorac. Surg. 2011, 40, e39-e42. [CrossRef] [PubMed]

9. Escobar, M.A., Jr.; Acierno, S.P. Laparoscopic resection of an intradiaphragmatic pulmonary sequestration: A case report and review of the literature. J. Pediatr. Surg. 2012, 47, 2129-2133. [CrossRef]

10. Joyeux, L.; Mejean, N.; Rousseau, T.; Couaillier, J.F.; Piard, F.; Sapin, E. Ectopic extralobar pulmonary sequestrations in children: Interest of the laparoscopic approach. J. Pediatr. Surg. 2010, 45, 2269-2273. [CrossRef] [PubMed]

11. Ahn, S.J.; Kim, E.Y.; Kim, J.H.; Byun, S.S.; Kim, H.S.; Choi, H.-Y.; Sun, Y.H. Successful endovascular treatment of bilateral intralobar pulmonary sequestration with a bridging isthmus in a child. Pediatr. Pulmonol. 2014, 49, E126-E129. [CrossRef]

12. Rokitskii, M.R.; Grebnev, P.N.; Osipov, A.Y. Sequestration of the lung. Child. Surg. 1998, 1, 54-57.

13. Lee, D.I.; Shim, J.K.; Kim, J.H.; Lee, H.Y.; Yun, Y.K.; Chun, K.J. Pulmonary sequestration with right coronary artery supply. Yonsei Med. J. 2008, 49, 507-508. [CrossRef] [PubMed]

14. Marinucci, B.T.; Maurizi, G.; Vanni, C.; Cardillo, G.; Poggi, C.; Pardi, V.; Inserra, A.; A Rendina, E. Surgical treatment of pulmonary sequestration in adults and children: Long-term results. Interact Cardiovasc. Thorac. Surg. 2020, 31, 71-77. [CrossRef] [PubMed]

15. Belchis, D.; Cowan, M.; Mortman, K.; Rezvani, B. Adenocarcinoma arising in an extralobar sequestration: A case report and review of the literature. Lung Cancer 2014, 84, 92-95. [CrossRef] [PubMed]

16. Becker, J.; Hernandez, A.; Dipietro, M.; Coran, A.G. Identical twins concordant for pulmonary sequestration communicating with the esophagus and discordant for the VACTERL association. Pediatr. Surg. Int. 2005, 21, 541-546. [CrossRef] [PubMed]

17. Yang, G.; Chen, L.; Xu, C.; Yuan, M.; Li, Y. Congenital bronchopulmonary foregut malformation: Systematic review of the literature. BMC Pediatr. 2019, 19, 305. [CrossRef]

18. Fenton, L.Z.; Williams, J.L. Bronchopulmonary foregut malformation mimicking neuroblastoma. Pediatr. Radiol. 1996, 26, 729-730. [CrossRef]

19. Borsellino, A.; Alberti, D.; Vavassori, D.; Pericotti, S.; Cheli, M.; Locatelli, G. Communicating bronchopulmonary foregut malformation involving a mixed sequestration/cystic adenomatoid malformation: A case report. J. Pediatr. Surg. $2002,37$. [CrossRef]

20. Eber, E. Antenatal diagnosis of congenital thoracic malformations: Early surgery, late surgery, or no surgery? Semin. Respir. Crit. Care Med. 2007, 28, 355-366. [CrossRef]

21. Liu, C.; Pu, Q.; Ma, L.; Mei, J.; Xiao, Z.; Liao, H.; Liu, L. Video-assisted thoracic surgery for pulmonary sequestration compared with posterolateral thoracotomy. J. Thorac. Cardiovasc. Surg. 2013, 146, 557-561. [CrossRef]

22. Razumovsky, A.Y.; Geraskin, A.V.; Sharipov, A.M. Endoscopic treatment of lung sequestration in children. Child. Surg. 2012, 5, $4-8$.

23. Albanese, C.T.; Sydorak, R.M.; Tsao, K.; Lee, H. Thoracoscopic lobectomy for prenatally diagnosed lung lesions. J. Pediatr. Surg. 2003, 38, 553-555. [CrossRef] [PubMed]

24. Yamasaki, N.; Tagawa, T.; Nakamura, A.; Tsuchiya, T.; Ashizawa, K.; Nagayasu, T. Video-assisted thoracoscopic resection for intralobar pulmonary sequestration. Gen Thorac. Cardiovasc. Surg. 2009, 57, 46-48. [CrossRef]

25. Avgerinos, D.; Reyes, A.; Plantilla, E.; Krikhely, M. Video-assisted thoracoscopic surgery for intralobar pulmonary sequestration. Cases J. 2008, 24, 269. [CrossRef]

26. Santiago-Martínez, S.; Guillén, G.; Laín, A.; López-Fernández, S.; Pérez, M.; Lloret, J. Endovascular embolization in the treatment of the pulmonary intralobar sequestration. Cir. Pediatr. 2017, 30, 57-63.

27. Cho, M.J.; Kim, D.Y.; Kim, S.C.; Kim, K.S.; Kim, E.A.; Lee, B.S. Embolization versus surgical resection of pulmonary sequestration: Clinical experiences with a thoracoscopic approach. J. Pediatr. Surg. 2012, 47, 2228-2233. [CrossRef]

28. Zhang, S.X.; Wang, H.D.; Yang, K.; Cheng, W.; Wu, W. Retrospective review of the diagnosis and treatment of pulmonary sequestration in 28 patients: Surgery or endovascular techniques? J. Thorac. Dis. 2017, 9, 5153-5160. [CrossRef]

29. Chakraborty, R.K.; Modi, P.; Sharma, S. Pulmonary Sequestration; StatPearls: Treasure Island, FL, USA, 2020. 